\title{
STUBURO STABILIZAVIMO IR KLUBO SĄNARIO MOBILUMĄ DIDINANČIŲ PRATIMŲ PROGRAMOS POVEIKIS PACIENTAMS, KURIE JAUČIA LËTINI NESPECIFINI APATINÉS NUGAROS DALIES SKAUSMĄ
}

\author{
Laura Urbanavičiūtė, Saulė Sipavičienė, Neringa Švedaitė \\ Lietuvos sporto universitetas
}

\section{SANTRAUKA}

Tyrimo pagrindimas. Viena iš apatinès nugaros dalies skausmo priežasčių yra liemens raumenų silpnumas bei sutrikusi giliujų liemens raumenų kontrolè. Norint išlaikyti juosmeninės stuburo dalies ir dubens stabilumą bei išvengti skausmo arba funkcijos sutrikimo, svarbu aktyvuoti daugini, skersini pilvo, vidinius įstrižinius ir didiji sẻdmens raumenis (Kim, Yim, 2020).

Tyrimo tikslas - ivvertinti stuburo stabilizavimo pratimų programos ir stuburo stabilizavimo kartu su klubo sąnario mobilumą didinančiais pratimais programos poveikị skausmui bei funkcinei būklei asmenims su lètiniu nespecifiniu apatinès nugaros dalies skausmu.

Metodai. Tyrime dalyvavo 20 pacientų, kurie skundèsi lètiniu nespecifiniu apatinès nugaros dalies skausmu, jie atsitiktiniu būdu buvo suskirstyti ị dvi grupes. Pirmos grupès tiriamųjų amžius buvo $24,90 \pm 3,70$ metų, antros $-30,00 \pm 4,30$ metų. Užsièmimai vyko tris kartus per savaitę, šešias savaites. Buvo vertinami skausmo, funkcinès būklès ir negalios, stuburo juosmeninès dalies paslankumo, šlaunies judesių amplitudès, pilvo raumenų statinès ištvermès pokyčiai.

Rezultatai. Po tyrimo skausmas sumažèjo abiejose grupėse $(\mathrm{p}<0,05)$. Juosmeninės stuburo dalies paslankumas abiejose grupėse pagerèjo $(\mathrm{p}<0,05)$. Šlaunies lenkimo, tiesimo, atitraukimo ir pritraukimo judesių amplitudès pirmoje grupejje padidèjo $(\mathrm{p}<0,05)$; antroje grupeje statistiškai reikšmingai nepakito. Funkcinė būklè pagerèjo abiejose grupėse $(p<0,05)$. Pilvo raumenų ištvermè pagerèjo abiejose grupėse $(\mathrm{p}<0,05)$. Po tyrimo, statistiškai reikšmingo vertintų rodiklių skirtumo tarp grupių nebuvo.

Išvados. Taikant tiek stuburo stabilizavimo pratimus, tiek stuburo stabilizavimo pratimus kartu su klubo sąnario mobilumą didinančiais pratimais, sumažèjo nugaros skausmas, pagerèjo juosmeninès nugaros dalies stabilumas, padidėjo šlaunies judesių amplitudè, tarp programų poveikio reikšmingo skirtumo nebuvo.

Raktažodžiai: stuburo stabilizavimo pratimai, klubo sąnario mobilumą didinantys pratimai, apatinès nugaros dalies skausmas.

\section{IVADAS}

Lètinis nespecifinis apatinès nugaros dalies skausmas - tai vienas dažniausių raumenų ir kaulų sistemos sutrikimų visame pasaulyje. Nespecifinis nugaros dalies skausmas būdingas maždaug 23 proc. suaugusiųų nuo 25 iki 74 metų amžiaus

Copyright $(2021$ Laura Urbanavičiūtė, Saulè Sipavičienė, Neringa Švedaitė. Published by Lithuanian Sports University.

This is an Open Access article distributed under the terms of the Creative Commons Attribution 4.0 International License, which permits unrestricted use, distribution, and reproduction in any medium, provided the original author and source are credited. 
(Haj et al., 2019), nes vis dažniau ir ilgesnị laikotarpị darbai atliekami statinejje padètyje, stovint arba sėdint. Žmonėms, daug laiko praleidžiantiems sėdimoje padẻtyje, susilpnèja kojų ir liemens raumenys (Park, Lee, 2019). Pagrindinė apatinès nugaros dalies skausmo priežastis - veiklos ribotumas, o tai galiausiai pablogina gyvenimo kokybę.

Labai dažnai dominuojantis skausmo veiksnys gali būti susijęs su judesiais ir laikysena, nurodant mechaninị sutrikimą. Propriocepcija - tai vienas pagrindinių komponentų, kuris atsakingas už motorinès sistemos ir sąnarinių struktūrų stabilumą kasdienės veiklos metu, judèjimo koordinavimą, be to, sumažina traumų riziką sportinės veiklos metu. Vadinasi, sutrikusi propriocepcija paveikia normalų koordinuotą žmogaus judèjimą. Sumažèjusi juosmens propriocepcija didina sportinių traumų riziką, skausmo intensyvumą, blogina juosmens funkciją (Zheng et al., 2019).

Nors klubo sąnario ir apatinès nugaros dalies funkcijos skirtingos, jos iš tikruju labai susijusios - kartu atlieka lenkimą ir tiesimą. Lètinis apatinès nugaros dalies skausmas gali turèti tiesioginès ir netiesioginès įtakos gretimų struktūrų disfunkcijai, tokių kaip juosmeninès nugaros dalies ir dubens. Vyresnio amžiaus asmenims, jaučiantiems šị skausmą, dažnai pasireiškia klubo sąnario skausmas ir rytinis sąstingis, o sportininkams - būna riboti judesiai per klubo sąnarị (Kim, Yim, 2020). Klubo sąnarys atlieka svarbų vaidmenị kinematinèje grandinèje, ypač fizinès veiklos metu stabilizuojant stuburą ir dubenį bei perduodant jègą iš kojų ị dubenị ir stuburą. Norint išlaikyti juosmens ir dubens stabilumą, ypač kryžkaulio sąnario, reikia aktyvuoti dauginị, skersini pilvo, vidinị ịstrižinị ir didịj (Kim, Yim, 2020).

Juosmeninès stuburo dalies stabilizavimo pratimai, skirti klubo sąnario raumenims stiprinti, sumažina juosmeninès dalies skausmą, padidina juosmeninès dalies raumenų jègą bei stabilumą. Klubo sąnario raumenų stiprinimo pratimai dažnai skiriami juosmeninès stuburo dalies skausmo profilaktikai (Cejudo et al., 2020). Liemens ir dubens stabilumo gerinimo pratimai sumažina skausmą ir pagerina judèjimo funkciją žmonėms, kurie jaučia lètinį nespecifinį apatinès nugaros dalies skausmą, nes jiems sumažeja juosmeninès dalies raumenų funkcija, pavyzdžiui, skersinio pilvo raumens susitraukimas (Jung et al., 2020).

Tyrimo tikslas - įvertinti stuburo stabilizavimo pratimų programos ir stuburo stabilizavimo kartu su klubo sąnario mobilumą didinančiais pratimais programos poveikị skausmui bei funkcinei būklei asmenims, kurie jaučia lètinị nespecifinị apatinès nugaros dalies skausmą. 


\section{METODAI}

Tiriamieji - tyrime dalyvavo 20 žmonių, kurie skundèsi lètiniu nespecifiniu apatinès nugaros dalies skausmu: 10 vyrų ir 10 moterų ( 1 lent.). Tiriamieji atsitiktine tvarka buvo susiskirstyti ị dvi grupes, po 10 žmonių. Pirmos grupès tiriamiesiems buvo taikomi stuburo stabilizavimo ir klubo sąnario mobilumą didinantys pratimai. Antros grupès - taikomi tik stuburo stabilizavimo pratimai.

1 lentelè. Tiriamųjų charakteristika

\begin{tabular}{|c|c|c|}
\hline \multirow{2}{*}{ Rodikliai } & \multicolumn{2}{|c|}{ Tiriamosios grupès } \\
\hline & I grupè & II grupè \\
\hline Tiriamųjų skaičius & 10 & 10 \\
\hline Lytis & $\begin{array}{l}5 \text { vyrai } \\
5 \text { moterys }\end{array}$ & $\begin{array}{l}5 \text { vyrai } \\
5 \text { moterys }\end{array}$ \\
\hline Amžius (metai) & $24,90 \pm 3,70$ & $30 \pm 4,30$ \\
\hline Skausmo trukmė (mèn.) & $13,70 \pm 7,51$ & $12 \pm 6,94$ \\
\hline Ūgis (cm) & $176,4 \pm 13,5$ & $176,6 \pm 8,2$ \\
\hline Svoris (kg) & $76,3 \pm 18,1$ & $74,7 \pm 16,3$ \\
\hline KMI $\left(\mathrm{kg} / \mathrm{m}^{2}\right)$ & $24,4 \pm 4,6$ & $23,7 \pm 3,4$ \\
\hline
\end{tabular}

Pastaba. Reikšmès pateiktos vidurkiais ir standartiniais nuokrypiais.

Santrumpos: KMI - kūno masès indeksas.

Tyrimo metodai. Eksperimentiniam tyrimui atlikti buvo gautas Lietuvos sporto universiteto bioetikos komiteto leidimas NR. MNL-KIN(M)-2020-241. Tyrimas atliktas 2019-2020 m. asmens sveikatos priežiūros ịstaigoje. Abi grupès šešias savaites, tris kartus per savaitę atliko tuos pačius aktyvius stabilizavimo pratimus, tačiau pirmos grupès tiriamieji papildomai atliko penkis klubo sąnario mobilumą didinančius pratimus. Tiriamųų grupių aktyvi kineziterapija buvo atliekama gulint ant mankštos kilimėlių, naudojantis savo kūno svoriu. Aktyvios pratimų programos trukmè - 30-45 min., tačiau pirmos grupès užsièmimai užtrukdavo 5-10 min. ilgiau. Pratimų programą sudarè: apšilimas, stuburo stabilizavimo, atsipalaidavimo ir klubo sąnario mobilumą didinantys pratimai. Abiejų grupių tiriamieji atliko tuos pačius apšilimo, stuburo stabilizavimo ir atsipalaidavimo pratimus. Tačiau pirmos grupès tiriamieji atliko papildomus klubo sąnario mobilumą didinančius pratimus (1 pav.).

Skaitinė skausmo vertinimo skalè „SVS“. Žmogaus, kuris patiria skausmą, prašoma skalëje pasirinkti skausmo intensyvumą nuo 0 (silpniausias) iki 10 (stipriausias) balų (Yao et al., 2020).

Stuburo juosmeninès dalies paslankumo testas pagal modifikuotą Šobert testą. Testo pradžioje tiriamasis prašomas stovèti tiesiai, nugara į vertintoją. Vertintojas tiriamajam pažymi pirmą tašką - horizontalioje linijoje ties viduriu tarp klubakau- 


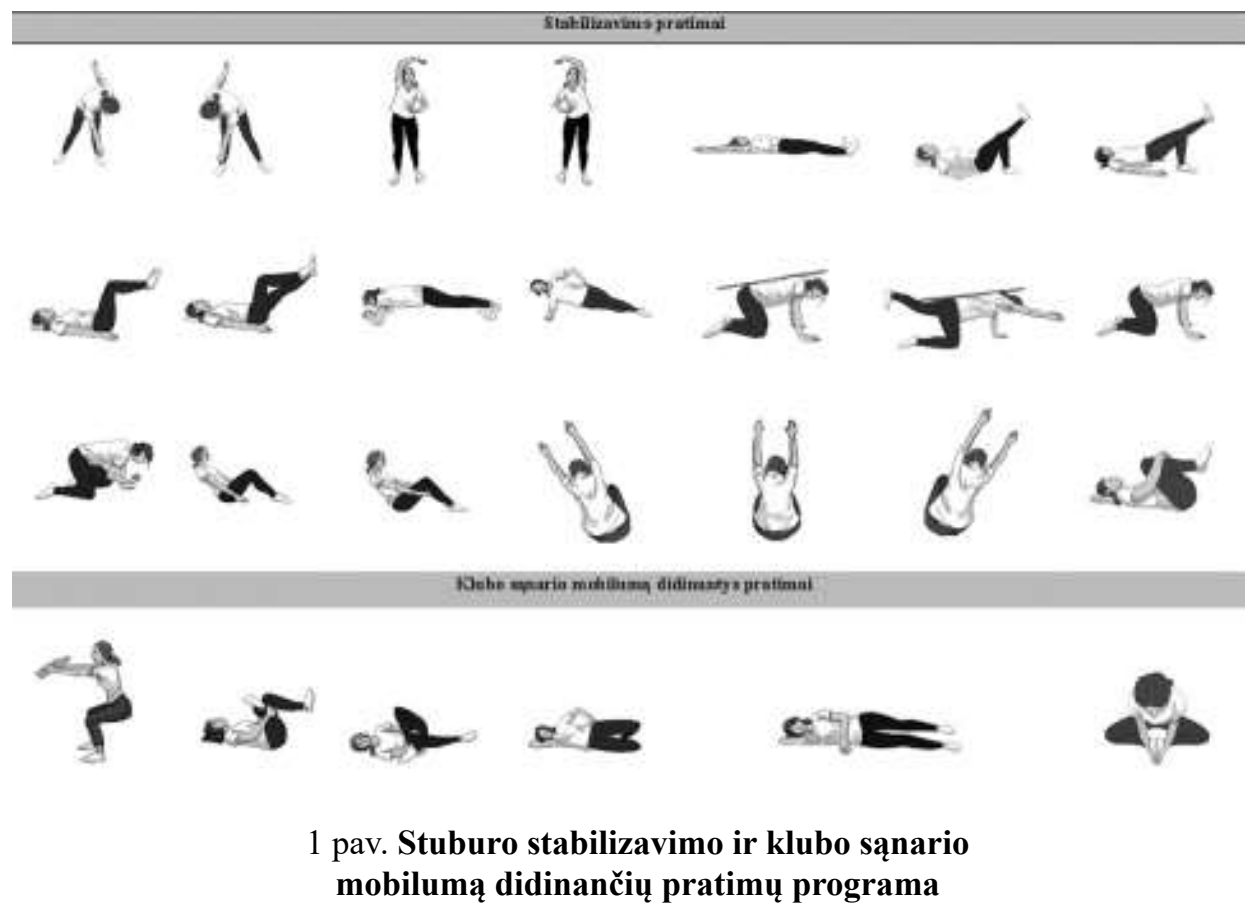

lio skiauterių. Antras ir trečias taškas pažymimas $10 \mathrm{~cm}$ virš ir $5 \mathrm{~cm}$ žemiau užpakalinio viršutinio klubakaulio dyglio, kuris vidutiniškai apima tik 4-5 juosmeninès dalies segmentus. Vèliau prašoma, kad tiriamasis lenktųsi žemyn link kojų pirštų, nesulenkdamas kelių, grižtu i i neutralią padètį. Apskaičiuojamas atstumas nuo pradinio taško iki tos vietos, kur juostelè kerta $15 \mathrm{~cm}$ žymę (Malik et al., 2016).

Goniometrija. Klubo sąnario judesių amplitudè buvo matuojama standartiniu goniometru. Klubo sąnario judesių amplitudès normos: lenkimas $0-120^{\circ}$, tiesimas $-0-20^{\circ}$, atitraukimas $-0-45^{\circ}$, pritraukimas $-0-30^{\circ}$. Atliekant lenkimo, pritraukimo ir atitraukimo matavimus, pacientų pradinè padètis - gulint ant nugaros ištiestomis kojomis.

Roland-Morris negalios klausimynas. Roland-Morris negalios klausimyną sudaro 24 teiginiai, susiję su asmens suvokiamu nugaros skausmu ir jo sukeliama negalia (Chiarotto et al., 2018). Skalè - nuo 0 iki 24 balų, kai didžiausias surinktų balų skaičius rodo maksimalią funkcinę negalią.

Statinès pilvo raumenų ištvermès testas. Testo atlikimo metu tiriamieji atsisèda taip, kad tarp liemens ir šlaunų bei tarp šlaunų ir blauzdų būtų $90^{\circ}$ kampas. Kineziterapeutas prilaiko tiriamujų pėdas. Tiriamajam už nugaros pastatoma pagalbinè priemonè, kuri padeda tinkamai nustatyti nugaros padètí, tam, kad nugara būtų 
išlaikyta $60^{\circ} \mathrm{kampu}$. Pagalbinė priemonė patraukiama ir prašoma, kad tiriamasis išsilaikytų horizontalioje padètyje kuo ilgiau. Testo baigimo laikas užfiksuojamas tada, kai tiriamasis nebeišlaiko padèties (Evans et al., 2007).

Matematinè statistika. Duomenys apdoroti taikant „IBM SPSS Statistics 21“ ir „Microsoft Excel 2010“ kompiuterinių programų paketus. Buvo apskaičiuojamas kiekybinių rodiklių aritmetinis vidurkis, standartinis nuokrypis (SN). Kineziterapijos pratimu programos poveikiui vertinti buvo naudojami neparametriniai Mann'o-Whithey'aus kriterijai nepriklausomoms imtims ir Wilcoxon'o - priklausomoms imtims lyginti. Nepriklausomų imčių Mann'o-Whithey'aus testas buvo taikomas lyginant nepriklausomas tiriamujų grupes (turinčius ir neturinčius nagrinejjamo požymio). Statistiškai reikšminga, kai p $<0,05$.

\section{TYRIMO REZULTATAI}

Po šešių savaičių tyrimo, kurio metu buvo taikoma skirtingos kineziterapijos pratimų programos, skausmo intensyvumo rodikliai statistiškai reikšmingai ( $\mathrm{p}<$ $0,05)$ sumažèjo abiejose tiriamujų grupèse (2 pav.).

Po šešiu savaičių tyrimo, kurio metu buvo taikoma skirtingos kineziterapijos pratimų programos, stuburo juosmeninès dalies paslankumo rodikliai statistiškai reikšmingai $(\mathrm{p}<0,05)$ padidèjo abiejose tiriamujų grupėse $(3 \mathrm{pav}$.$) .$

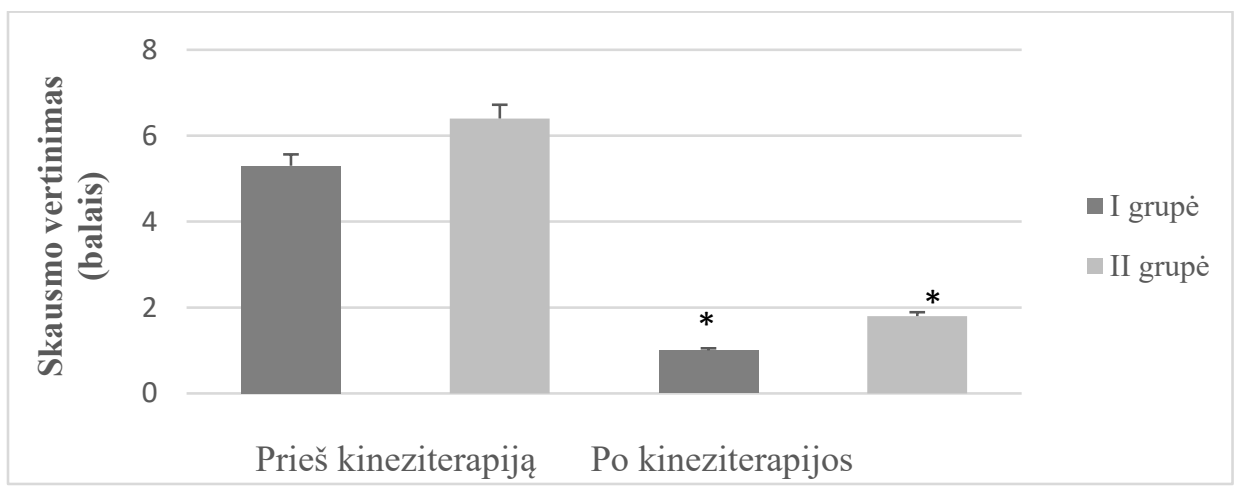

Pastaba. ${ }^{*}-\mathrm{p}<0,05$ palyginus rodiklius prieš kineziterapiją ir po jos.

2 pav. Tiriamųjų skausmo pokyčiai po kineziterapijos pratimų taikymo 


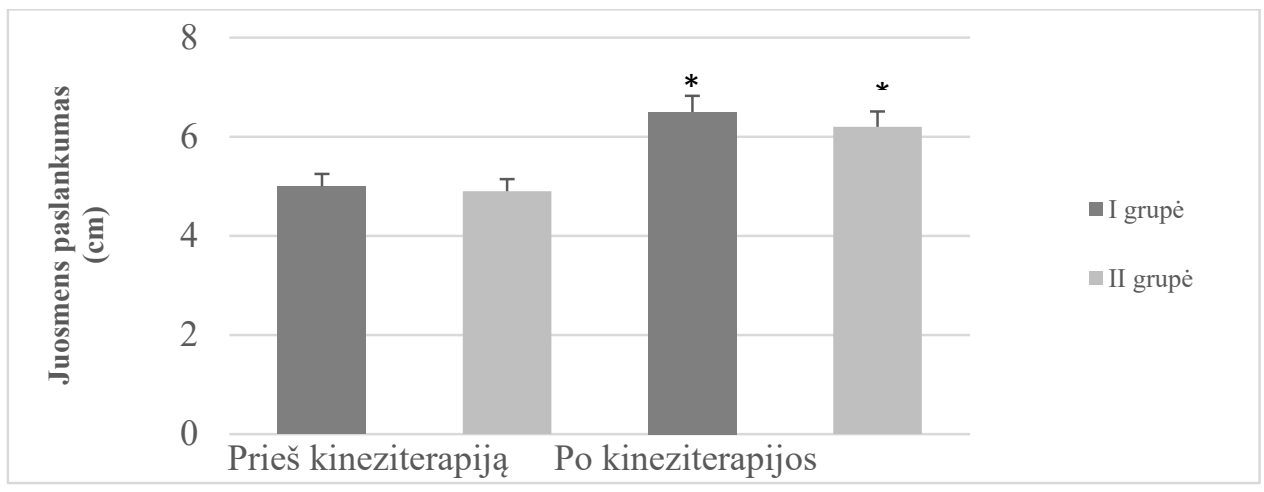

Pastaba. $*-p<0,05$ palyginus rodiklius prieš kineziterapiją ir po jos.

3 pav. Juosmens paslankumo pokyčiai po kineziterapijos pratimų taikymo

Po šešių savaičių tyrimo, kurio metu buvo taikoma dvi skirtingos kineziterapijos pratimu programos, šlaunies lenkimo, tiesimo, atitraukimo ir pritraukimo judesių amplitudès rodikliai statistiškai reikšmingai $(\mathrm{p}<0,05)$ pagerėjo pirmoje grupejje (2 lent.).

2 lentelè. Šlaunies judesių amplitudès pokyčiai po kineziterapijos pratimų taikymo

\begin{tabular}{|l|l|l|l|l|}
\hline \multirow{2}{*}{$\begin{array}{c}\text { Klubo sąnario } \\
\text { amplitudes } \\
\text { (laipsniai) }\end{array}$} & $\begin{array}{c}\text { Irieš kinezite- } \\
\text { rapiją }\end{array}$ & $\begin{array}{c}\text { Po kinezitera- } \\
\text { pijos }\end{array}$ & $\begin{array}{c}\text { Prieš kinezite- } \\
\text { rapiją }\end{array}$ & $\begin{array}{c}\text { Po kinezitera- } \\
\text { pijos }\end{array}$ \\
\hline Lenkimas & $114^{\circ}$ & $122^{\circ}$ & $117^{\circ}$ & $119^{\circ}$ \\
\hline Tiesimas & $14^{\circ}$ & $22^{\circ}$ & $19^{\circ}$ & $20^{\circ}$ \\
\hline Atitraukimas & $30^{\circ}$ & $45^{\circ}$ & $38^{\circ}$ & $39^{\circ}$ \\
\hline Pritraukimas & $27^{\circ}$ & $31^{\circ}$ & $25^{\circ}$ & $25^{\circ}$ \\
\hline
\end{tabular}

Po šešių savaičių tyrimo, kurio metu buvo taikoma dvi skirtingos kineziterapijos pratimų programos, pilvo raumenų ištvermès rodikliai statistiškai reikšmingai $(\mathrm{p}<0,05)$ pagerejo abiejose tiriamujjų grupèse.

Po šešių savaičių tyrimo, kurio metu buvo taikoma dvi skirtingos kineziterapijos pratimu programos, „Roland-Morris“ negalios indekso rodikliai statistiškai reikšmingai $(\mathrm{p}<0,05)$ padidejo abiejose tiriamujų grupèse. 


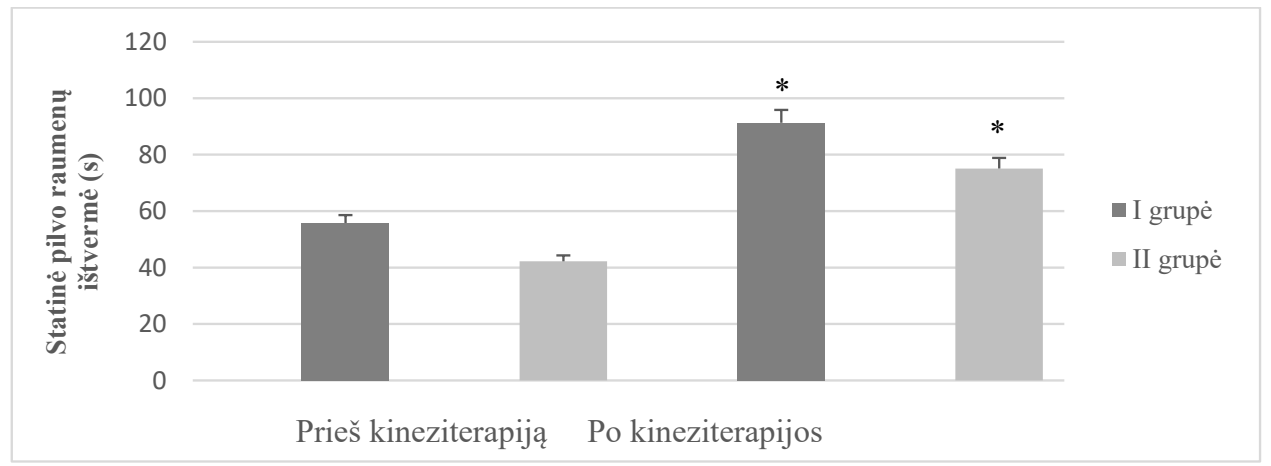

Pastaba. ${ }^{*}-\mathrm{p}<0,05$ palyginus rodiklius prieš kineziterapiją ir po jos.

4 pav. Pilvo raumenų ištvermès pokyčiai po kineziterapijos pratimų taikymo

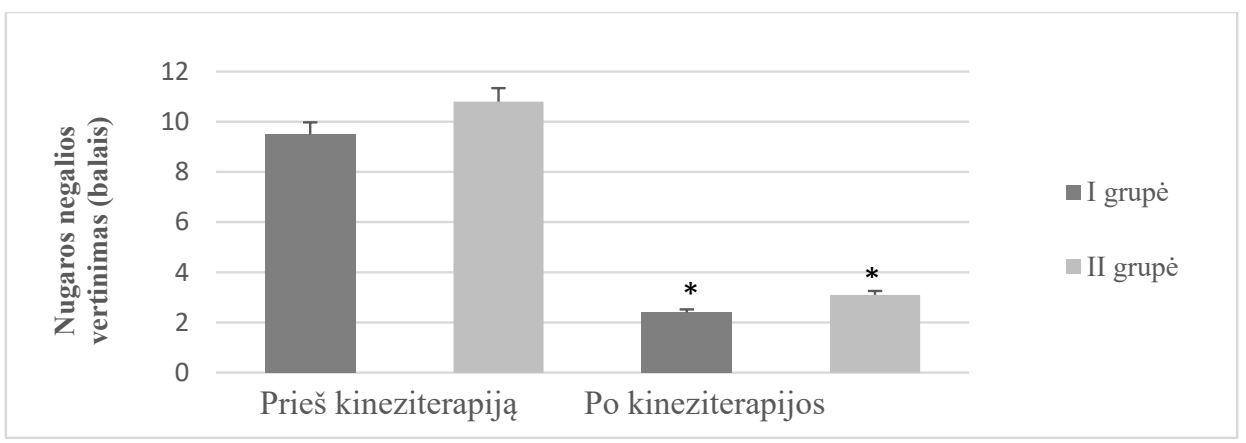

Pastaba. ${ }^{*}-\mathrm{p}<0,05$ palyginus rodiklius prieš kineziterapiją ir po jos.

\section{5 pav. „Roland-Morris“ negalios klausimyno vertinimas} po kineziterapijos pratimų taikymo

\section{REZULTATŲ APTARIMAS}

Mūsų tyrimo duomenimis, po šešias savaites taikytų stuburo stabilizavimo pratimų ir stuburo stabilizavimo kartu su klubo sąnario mobilumą didinančių pratimų programų sumažèjo skausmo intensyvumas, padidejo klubo sąnario judesių amplitudès bei pagerejjo stuburo stabilumas. Vertinant skirtingas kineziterapijos pratimu programas, pastebètas reikšmingas pokyčių skirtumas tik grupių viduje. 
Panašūs B. Kim et al. (2020) tyrimo duomenys: stuburo stabilizavimo ir klubo sąnario mobilumą didinančių pratimų bei stuburo stabilizavimo pratimų programos vertintiems rodikliams statistiškai reikšmingą skirtumą tyrejjai nustatè tik tempimo grupès ir stiprinimo grupès viduje, tačiau tarp grupių reikšmingo skirtumo nebuvo. Mūsų tyrimo duomenimis, taikant stuburo stabilizavimo ir klubo sąnario mobilumą didinančius pratimus rezultatas buvo daug veiksmingesnis ir reikšmingesnis nei taikant tik stuburo stabilizavimo pratimus. S. Lee et al. (2015) atlikto tyrimo duomenimis, pacientams, kuriems buvo taikomi sąnario mobilumą didinantys pratimai ir juosmens stabilumą gerinantys pratimai, statistiškai reikšmingai sumažèjo apatinès nugaros dalies skausmo intensyvumas.

S. Winter (2015) duomenys rodo, kad asmenų, patiriančių nespecifinį lètinị arba pasikartojantị apatinès nugaros dalies skausmą, rezultatai po klubo sąnario mobilumą didinančių pratimų buvo statistiškai reikšmingai geresni nei klubo sąnarị supančiu raumenų tempimo ir stiprinimo pratimų taikymo rezultatai. Mūsų tyrime nustatyta, kad klubo sąnariui skirti pratimai gali būti naudingi siekiant pagerinti funkcinę būklę ir sumažinti apatinès nugaros dalies skausmą. Pagerèjimas nustatytas visose tiriamųu grupėse: klubo sąnario tempimo, daugiakrypčių klubo sąnario tempimo ir klubo sąnario jègos stiprinimo, bet didesnių skirtumų nerasta.

Panašūs ir M. Aboufazeli et al. (2020) tyrimo, kuriame buvo lyginami dviejų tipų kineziterapijos pratimai: stuburo stabilizavimo ir klubo sąnario paslankumo didinimo, rezultatai. Buvo atliekamos 24 pratimų sesijos: aštuonias savaites, tris kartus per savaitę, rezultatai reikšmingai pagerejo po abiejų tipų pratimų taikymo. Taip pat, autorių teigimu, abiejose grupèse skausmas sumažèjo statistiškai reikšmingai. Autoriai nurodè, kad asmenims, kuriems taikyti klubo sąnario paslankumo didinimo pratimai, skausmas sumažejo 65 proc., o asmenims, kuriems taikyti stuburo stabilizavimo pratimai, sumažejo tik 47 proc.

S. Park, M. Lee (2019), D. Niederer ir J. Mueller (2020) tyrimų duomenimis, atliekant tik stuburo stabilizavimo pratimus buvo didesnis juosmeninès stuburo dalies stabilumas. Autoriai teigia, kad progresyvi stuburo stabilizavimo pratimu programa didina stuburo stabilumą bei yra pranašesnè ir veiksmingesnè, palyginus su ịprasta kineziterapijos programa.

Apibendrinant tyrimo rezultatus galima teigti, kad stuburo stabilizavimo pratimų ir stuburo stabilizavimo kartu su klubo sąnario mobilumą didinančiais pratimais programos sumažino apatinės nugaros dalies skausmą, pagerino juosmeninès dalies stabilumą ir funkcinę būklę. 


\section{IŠVADOS}

Taikant tiek stuburo stabilizavimo pratimus, tiek stuburo stabilizavimo pratimus kartu su klubo sąnario mobilumą didinančiais pratimais, sumažèjo nugaros skausmas, pagerejo juosmeninès nugaros dalies stabilumas, padidejo šlaunies judesių amplitudè, o tarp pratimų programų poveikio reikšmingo skirtumo nebuvo.

\section{LITERATŪRA}

Aboufazeli, M., Afshar-Mohajer, N., Jafarpisheh, M. S., Heidari, M., \& Akbari, M. (2020). Recovery of the Lumbar Multifidus Muscle Size in Chronic Low Back Pain Patients by Strengthening Hip Abductors: A Randomized Clinical Trial. Journal of Bodywork and Movement Therapies.

Cejudo, A., Moreno-Alcaraz, V. J., Izzo, R., et al. (2020). External and total hip rotation ranges of motion predispose to low back pain in elite Spanish inline hockey players. International Journal of Environmental Research and Public Health, 17 (13), 4858.

Chiarotto, A., Boers, M., Deyo, et al. (2018). Core outcome measurement instruments for clinical trials in nonspecific low back pain. Pain, 159 (3), 481.

Ghaderi, F., Mohammadi, K., Sasan, R. A., et al. (2016). Effects of stabilization exercises focusing on pelvic floor muscles on low back pain and urinary incontinence in women. Urology, 93, 50-54.

Evans, K., Refshauge, K. M., \& Adams, R. (2007). Trunk muscle endurance tests: reliability, and gender differences in athletes. Journal of Science and Medicine in Sport, 10 (6), 447-455.

Haj, A., Weisman, A., \& Masharawi, Y. (2019). Lumbar axial rotation kinematics in men with non-specific chronic low back pain. Clinical Biomechanics, 61, 192-198.

Hlaing, S. S., Puntumetakul, R., Wanpen, S., \& Boucaut, R. (2020). Balance Control in Patients with Subacute Non-Specific Low Back Pain, with and without Lumbar Instability: A Cross-Sectional Study. Journal of Pain Research, 13, 795.

Yao, M., Xu, B. P., Li, Z. J., et al. (2020). A comparison between the low back pain scales for patients with lumbar disc herniation: validity, reliability, and responsiveness. Health and Quality of Life Outcomes, 18 (1), 1-12.

Jung, S. H., Hwang, U. J., Ahn, et al. (2020). Lumbopelvic motor control function between patients with chronic low back pain and healthy controls: a useful distinguishing tool: The STROBE study. Medicine, 99 (15).

Kim, B., \& Yim, J. (2020). Core Stability and Hip Exercises Improve Physical Function and Activity in Patients with Non-Specific Low Back Pain: A Randomized Controlled Trial. The Tohoku Journal of Experimental Medicine, 251 (3), 193-206.

Lee, S., \& Kim, S. Y. (2015). Effects of hip exercises for chronic low-back pain patients with lumbar instability. Journal of physical therapy science, 27 (2), 345-348

Malik, K., Sahay, P., Saha, S., \& Das, R. K. (2016). Normative Values of Modified-Modified Schober Test in Measuring Lumbar Flexion and Extension: A Cross-Sectional Study. International Journal of Health Science and Research, 6, 177-187.

Niederer, D., \& Mueller, J. (2020). Sustainability effects of motor control stabilisation exercises on pain and function in chronic nonspecific low back pain patients: a systematic review with meta-analysis and metaregression. PloS one, 15 (1), e0227423.

Park, S. H., \& Lee, M. M. (2019). Effects of a progressive stabilization exercise program using respiratory resistance for patients with lumbar instability: A randomized controlled trial. Medical science monitor: international medical journal of experimental and clinical research, 25, 1740.

Winter, S. (2015). Effectiveness of targeted home-based hip exercises in individuals with non-specific chronic or recurrent low back pain with reduced hip mobility: A randomised trial. Journal of back and musculoskeletal rehabilitation, 28 (4), 811-825.

Zheng, Y. L., Wang, X. F., Chen, B. L., et al. (2019). Effect of 12-week whole-body vibration exercise on lumbopelvic proprioception and pain control in young adults with nonspecific low back pain. Medical science monitor: international medical journal of experimental and clinical research, 25, 443. 


\title{
EFFECT OF SPINAL STABILIZATION AND HIP JOINT MOBILITY ENHANCING EXERCISE PROGRAMS IN PERSONS WITH NON-SPECIFIC CHRONIC LOWER BACK PAIN
}

\author{
Laura Urbanavičiūtė, Saulė Sipavičienė, Neringa Švedaitė \\ Lithuanian Sports University
}

\section{ABSTRACT}

Background. One of the main reasons of lower back pain is the weakness of trunk muscle and impaired control of deep trunk muscles. In order to maintain lumbar spine and pelvis stability, and to avoid pain or dysfunction, it is important to activate the multifidus muscle, transversus abdominis, internal oblique and gluteus maximus muscles (Kim \& Yim, 2020).

Aim. To evaluate the effect of spinal stabilization exercising program and spinal stabilization with hip joint mobility enhancing exercise program on pain and functional state for people with chronic non-specific lower back pain.

Methods. The study involved 20 subjects with lower back pain randomly divided into two groups: I group and II group. The first group had an age average of $24,90 \pm 3,70$ years, while the average age of the second group was $30 \pm 4,30$ years. All groups participated in a six-week exercise program three times a week. Measurements assessed: pain, functional disability, trunk mobility, femur measurement of the amplitude, static endurance of abdominal muscles.

Results. After the study pain decreased in both groups $(\mathrm{p}<0.05)$. Lower back instability increased in both groups $(\mathrm{p}<0.05)$. Femur motion amplitude increased when flexing and extending, abduction and adduction in the first group $(\mathrm{p}<0.05)$. The second group remained statistically significantly unchanged. Functional disability decreased in the both groups $(p<0.05)$. Abdominal muscles static endurance decreased $(\mathrm{p}<0.05)$. After the study no significant difference in the assessed indicators between the groups was found.

Conclusions. The application of both spinal stabilization and spinal stabilization combined with hip joint mobility enhancing exercises reduced back pain, improved lumbar back stability, increased femur movement amplitude, however the study found no significant difference between programs.

Keywords: spinal stability exercise, hip mobility exercise, low back pain.

Gautas 20210329

Priimtas 20210510 